\title{
A agenda educacional do Banco Mundial em tempos de ajuste e pandemia
}

\author{
João Márcio Mendes Pereira ${ }^{1}$ \\ ORCID https://orcid.org/0000-0003-3272-0312
}

\section{Resumo}

0 artigo discute a agenda educacional do Banco Mundial em perspectiva histórica, questionando se ela sofreu alguma mudança devido à eclosão da contaminação pelo novo coronavírus (Sars-cov2) em escala global, responsável pela pandemia da doença denominada Covid-19. Com base na documentação da própria instituição e tomando como referência o caso brasileiro, argumenta-se que não houve mudança no seu caráter neoliberal, vigente desde a década de 1980. Ao mesmo tempo em que o Banco apoia as medidas de urgência tomadas pelos governos dos países em desenvolvimento (clientes da instituição) para amenizar os impactos da pandemia - o que necessariamente leva ao aumento do gasto público -, a instituição continua a condicionar a liberação de recursos em troca da adoção de políticas neoliberais, além de manter a primazia normativa do ajuste fiscal como base da ação dos governos desses países no pós-pandemia. Inicialmente, o artigo apresenta e problematiza as diferentes atividades realizadas pelo Banco (concessão de empréstimos, aconselhamento, assistência técnica, advocacy em favor de determinadas pautas, articulação de iniciativas multilaterais e pesquisa econômica). A seguir, analisa a evolução histórica da agenda educacional da instituição, à luz do seu programa político mais geral. Por fim, discute a atuação do Banco na educação brasileira, com base em um exame da carteira de empréstimos e em documentos estratégicos da entidade para o país, que abrangem o período 2017-20, aos quais a sua agenda educacional está subordinada.

\section{Palavras-chave}

Banco Mundial - Ajuste fiscal - Neoliberalismo - Pandemia.

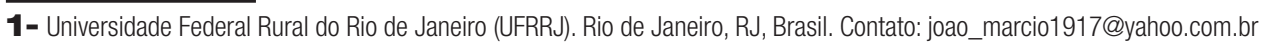




\section{The educational agenda of the World Bank in times of fiscal adjustment and pandemic}

\section{Abstract}

This article discusses the educational agenda of the World Bank from a historical perspective, asking whether it has undergone any changes due to the outbreak of contamination on a global scale caused by the new coronavirus (Sars-cov2), responsible for the Covid-19 pandemic. Based on the institution's documentation and taking as a reference the Brazilian case, it is argued that no change has occurred in its neoliberal nature, in force since the 1980s. At the same time that the Bank supported the measures of urgency adopted by governments of developing countries (clients of the institution) to soften the impacts of the pandemic - which necessarily results in an increase in public expenditure -, the institution continues to condition the release of funds on the adoption of neoliberal policies, as well as maintaining the normative primacy of the fiscal adjustment as the basis of action for governments of these countries in the postpandemic period. Initially, the article presents and problematizes the different activities carried out by the Bank (the granting of loans, advice, technical assistance, advocacy in favor of determined agenda, the linking of multilateral initiatives and economic research). Following this, it analyzes the historical evolution of the educational agenda of the institution, in light of its more general political program. Finally, it discusses the action of the Bank in Brazilian education, based on an examination of the organization's loan portfolio and strategic documents for Brazil, covering the period 2017-20, to which its educational agenda was subordinated.

\section{Keywords}

World Bank - Fiscal adjustment - Neo-liberalism - Pandemic.

Segundo o Banco Mundial, a pandemia do Covid-19 lançou a economia global na mais profunda recessão desde a Segunda Guerra Mundial. No que diz respeito à educação, a pandemia escancarou as profundas desigualdades que marcam a vida de centenas de milhões de crianças, jovens e adultos, e não apenas nos países em desenvolvimento. No planeta inteiro, em meados de 2020, cerca de 1,5 bilhão de pessoas estavam fora da escola, enquanto no Brasil eram mais de 180 mil escolas fechadas e 47 milhões de alunos sem aulas presenciais. Chamado a atuar como "bombeiro", o Banco Mundial anunciou, durante a reunião do G20 em março de 2020, um pacote de ajuda rápida de US\$ 14 bilhões, e mais até US\$ 160 bilhões nos quinze meses seguintes em empréstimos e créditos para mais de cem países pobres e de renda média. ${ }^{2}$

2- 'Remarks by World Bank Group President David Malpass on G20 Finance Ministers Conference Call on COVID-19'. March 23, 2020. https://www.worldbank.org/en/news/speech/2020/03/23/remarks-by-world-bank-group-president-david-malpass-on-g20-finance-ministersconference-call-on-covid-19 Acesso em: 28 jul.20. 
Este artigo discute a agenda educacional do Banco Mundial em perspectiva histórica, argumentando que a emergência da pandemia não tem sido respondida pela instituição com uma revisão da sua agenda política neoliberal. Ao mesmo tempo em que, de maneira geral, o Banco apoia as medidas de urgência tomadas pelos governos para amenizar os impactos da pandemia - o que necessariamente leva ao aumento do gasto público -, a instituição continua a condicionar a liberação de recursos em troca da adoção de políticas neoliberais, além de manter a primazia normativa do ajuste fiscal como base da ação dos governos dos países em desenvolvimento no pós-pandemia.

Inicialmente, o artigo discute as atividades que o Banco Mundial realiza e como ele atua na educação. Em seguida, apresenta e analisa as linhas gerais da agenda educacional da instituição, para depois abordar a atuação do Banco na educação brasileira, com destaque para o quadriênio 2017-2020.

\section{O que faz o Banco Mundial e como atua na educação?}

A origem do Banco Mundial remonta à criação do Banco Internacional para a Reconstrução e Desenvolvimento (BIRD), produto da conferência de Bretton Woods ocorrida em julho de 1944, quando também se decidiu a criação do Fundo Monetário Internacional (FMI). Nas décadas seguintes, em torno e ligados ao BIRD surgiram: o Instituto de Desenvolvimento Econômico em 1955 (renomeado de Instituto Banco Mundial em 2000); a Corporação Financeira Internacional em 1956; a Associação Internacional de Desenvolvimento em 1960; o Centro Internacional para Conciliação de Divergências em Investimentos em 1966; e a Agência Multilateral de Garantia em Investimento em 1988. Esse conjunto de instituições forma o Grupo Banco Mundial, cuja sede está em Washington, DC (EUA). 0 chamado "Banco Mundial” corresponde ao BIRD e à Associação Internacional de Desenvolvimento (AID).

Fundamentalmente, o Banco Mundial realiza quatro tipos de atividade: $a$ ) empréstimos e créditos para projetos e políticas; $b$ ) aconselhamento, assistência técnica e advocacia em favor de determinada agenda de políticas; c) pesquisa econômica especializada em todas as áreas do desenvolvimento; $d$ ) mobilização e articulação de agentes públicos e privados para iniciativas multilaterais globais.

A atividade financeira é vital para a reprodução e expansão do Banco Mundial. É por meio do dinheiro que o Banco veicula e difunde suas prescrições políticas aos governos dos países em desenvolvimento. Os empréstimos e créditos embutem condicionalidades (exigências), que podem ser pontuais (restritas ao âmbito de projetos), ou bastante amplas (quando ligadas a empréstimos de ajuste) e incidir sobre a configuração das políticas públicas e da própria administração pública. Embora as condicionalidades possam ter um caráter coercitivo maior ou menor, dependendo do país e da sua situação econômica, em geral são mais eficazes quando há interlocutores domésticos comprometidos com elas e com poder para implantá-las. Em casos assim, políticos locais costumam utilizar tais condicionalidades como imperativos políticos contra seus adversários imediatos, a fim de aprovar reformas impopulares. Em geral, isso ocorre quando estão em jogo reformas estruturais de "primeira geração", voltadas para o ajuste macroeconômico e a austeridade fiscal. De implantação relativamente simples, rápida e drástica, tais reformas têm alta 
visibilidade pública e efeitos imediatos, mas os custos políticos são amplamente diluídos pela população.

Nessas situações, normalmente contextos de crise, a tomada de decisão pode ser conduzida por uma elite insulada no topo do Poder Executivo. Por outro lado, quando a tomada de decisão é aberta a um grande número de interlocutores do sistema político, a eficácia das condicionalidades tende a ser muito mais difícil. É o caso de reformas institucionais amplas, de "segunda geração", voltadas para o redesenho de políticas públicas específıcas (tais como educação, saúde, meio ambiente) e a reconfiguração da própria estrutura política e administrativa do Estado, como, por exemplo, a desconstitucionalização do gasto público, a independência do Banco Central, as mudanças regulatórias abrangentes, as privatizações politicamente mais difíceis, etc. Tais reformas têm tramitação lenta e complexa, e afetam interesses de grupos sociais específicos, tendencialmente com maior capacidade de vocalização e resistência (NAÍM, 1994; BANCO MUNDIAL, 1997).

Processos assim envolvem maior concertação política e podem exigir que o Banco Mundial exerça mais abertamente a advocacy pelas reformas. Vale frisar que o Banco empresta não apenas para a União, mas também para estados e municípios, o que, em países federativos (como o Brasil), pode levar à capilarização de suas operações por todo o território nacional. Os empréstimos normalmente induzem a mudanças na composição, no grau de prioridade e no destino das despesas públicas, pois os governos devem desembolsar uma contrapartida financeira, e depois têm de reembolsar o Banco Mundial, tido como credor preferencial, e em uma moeda forte.

A segunda atividade consiste em fornecer aconselhamento e assistência técnica aos governos dos países em desenvolvimento. Historicamente, o Banco sempre negociou com grupos muito seletos de interlocutores nacionais (em geral, da área econômica ou de planejamento), às vezes treinados e socializados em circuitos internacionais de formação de tecnocratas, dos quais o próprio Banco faz parte como educador. A partir da década de 1980, graças a pressões crescentes por transparência e accountability, o Banco foi obrigado a se abrir a processos de consulta pública e participação de grupos variados (GWIN, 1997; BABB, 2009). Ao mesmo tempo, à medida que a agenda de políticas do Banco se ampliou e se diversificou, passando a englobar todas as áreas do desenvolvimento, tornou-se impossível implementá-la de cima para baixo, razão pela qual o Banco teve de assumir também um papel crescente de advocacy, a fim de mobilizar apoio político em favor de determinadas pautas. Significa dizer que, nos países clientes, o Banco Mundial se relaciona não apenas com nichos da burocracia, mas também com atores da sociedade civil.

A terceira atividade consiste na produção de conhecimento especializado sobre desenvolvimento internacional. Com ampla difusão, a pesquisa do Banco envolve: a) a construção de conceitos, definições e normas, com o objetivo de delimitar os termos legítimos do debate sobre desenvolvimento; b) a elaboração de indicadores (métricas) e classificações, com base nos quais se constroem rankings internacionais cada vez mais abrangentes sobre a "qualidade" das políticas públicas e do "ambiente institucional" necessários para se fazer business nos países clientes; c) explicações sobre as causas dos problemas do desenvolvimento e a pregação de medidas que os governos devem 
ou não adotar, e de que modo, para superá-los. Além da pesquisa baseada em seu próprio staff ou encomendada a consultores externos, o Banco também atua como caixa de ressonância e correia de transmissão de determinados modelos, conceitos e ideias produzidos por outras organizações.

A legitimidade intelectual do Banco se baseia na premissa da neutralidade do saber técnico e no caráter multilateral da instituição (percebido como menos politizado do que organizações bilaterais de ajuda internacional). Embora o Banco Mundial cultive a aparência de neutralidade técnica, a pesquisa por ele realizada é essencialmente normativa. A ideia de neutralidade do conhecimento despreza qualquer consideração sobre o contexto econômico, social, político e ideológico no qual todo conhecimento é produzido, os interesses em disputa e as funções que o conhecimento pode ou deve cumprir (VAN WAEYENBERGE; FINE, 2011). De modo geral, premido pela necessidade de realizar empréstimos, o Banco promove investigações que legitimem a sua agenda de políticas e suas prioridades financeiras (BROAD, 2006). Há, portanto, fatores estruturais que enquadram e moldam a atividade de pesquisa por ele realizada (STERN; FERREIRA, 1997). Em uma instituição orientada para empréstimos atrelados a prescrições políticas, a pesquisa tem de ser útil a tais operações.

A quarta atividade principal do Banco Mundial consiste em mediar, destilar e articular interesses, visões e normas, e canalizá-los em iniciativas e campanhas multilaterais globais que envolvam governos, empresas, ONGs, fundações filantrópicas, setores da academia e outras organizações internacionais em matéria de saúde, meio ambiente, educação, entre outros. De fato, parte considerável da influência do Banco Mundial se deve à sua capacidade de estabelecer conexões materiais e acordos - mais programáticos ou mais pragmáticos - entre agentes públicos e privados em torno de determinadas pautas de desenvolvimento.

\section{Linhas gerais da agenda educacional do Banco Mundial}

A atuação do Banco Mundial na educação começou tardiamente, quando comparado à Organização das Nações Unidas. Apenas em 1962 a instituição fez o primeiro empréstimo para o setor, concentrando-se, nos anos seguintes, em financiar a construção de infraestrutura escolar (prédios, bibliotecas, laboratórios) e o treinamento de trabalhadores em grandes projetos de desenvolvimento (barragens, estradas, etc.). Ou seja, no início os projetos de educação privilegiavam mais os aspectos de infraestrutura física e o treinamento para tarefas específicas (PEREIRA, 2010).

Durante a gestão de Robert McNamara (1968-81), a educação passou a ser considerada como um setor fundamental para se levar adiante o "combate à pobreza", bandeira encampada por McNamara como parte da sua estratégia mais ampla de promover o desenvolvimento capitalista como medida preventiva contra revoltas e revoluções sociais no então chamado Terceiro Mundo. Segundo ele, "numa sociedade que está se modernizando, segurança significa desenvolvimento [...]. Sem desenvolvimento interno, pelo menos em grau mínimo, ordem e estabilidade são impossíveis" (McNAMARA, 1968, p. 173). Com essa perspectiva, os projetos de educação financiados pelo Banco Mundial se voltaram para grupos sociais focalizados, que viviam em condições de pobreza extrema, 
a fim de melhorar o seu "capital humano" e a sua inserção atomizada em atividades mercantis lucrativas - em geral, associadas a atividades agrícolas. Ou seja, tais projetos combinaram a incorporação tardia do conceito de capital humano com a adoção do princípio da focalização em grupos populacionais específicos, imunizando o "investimento nos indivíduos" contra qualquer consideração redistributivista.

Durante a década de 1980, a neoliberalização do capitalismo internacional fortaleceu o papel do Banco Mundial como líder intelectual do "ajuste estrutural" (STERN; FERREIRA, 1997; PEREIRA, 2010). A expressão nasceu de uma nova modalidade de empréstimo da instituição iniciada em 1980, de desembolso rápido, com o propósito de financiar a adoção de políticas (e não a execução de projetos). Tratava-se, pois, de um tipo de atuação mais politizada e intrusiva, baseada em condicionalidades mais abrangentes. A crise da dívida externa dos países da periferia do sistema (principalmente na América Latina e parte da África) criou as condições para que os empréstimos de ajuste fossem amplamente demandados, em troca da realização de medidas de liberalização econômica. Nesse período, a agenda do Banco Mundial se concentrou na promoção do ajuste macroeconômico e fiscal, a fim de garantir o pagamento dos credores privados externos (BABB, 2009; TOUSSAINT, 2006). Porém, além das políticas macroeconômica e fiscal, todas as políticas sociais, entre as quais a educação, também foram "ajustadas". Impulsionada pela instituição, a ideologia hipermercadista - baseada na oposição entre Estado e mercado - buscou legitimar uma visão de educação como um mercado aberto ao investimento privado. Durante esse período, o ajuste fiscal incidiu fortemente sobre o orçamento da educação e das demais políticas sociais, induzindo uma reestruturação de toda a área social rumo à focalização do gasto público nos mais pobres, por um lado, e à recuperação de custos (cobrança de taxas aos usuários) sempre que possível.

A partir de 1990, embalado pela transição acelerada das sociedades do Leste ao capitalismo neoliberal - batizada então de "terapia de choque" -, o Banco Mundial ampliou bastante a sua agenda política para além da ênfase no ajuste macroeconômico, visando à reestruturação não apenas das economias, mas também das sociedades. No campo da educação, a instituição levou adiante a bandeira da "educação para todos”, o que na prática significava comprometer-se com o esforço multilateral de universalização do acesso à educação básica em poucos anos. Para o Banco, tal meta somente seria atingida se os Estados nacionais focalizassem o gasto público nos segmentos mais pobres da população, a fim de melhorar o capital humano dos indivíduos e elevar a sua produtividade nas relações de mercado. Em nome da "inclusão de todos" e da "redução da pobreza”, o gasto público em educação não deveria mais seguir critérios universais de distribuição, mas sim focalizados. Desse modo, enquanto para os mais pobres o Estado forneceria educação básica, para os que pudessem pagar por ela - conforme linhas de pobreza definidas de forma bastante controversa - o mercado seria o caminho. A primazia normativa do ajuste fiscal se manteve incólume. Gradativamente, a agenda educacional da instituição tornou-se mais ambiciosa, passando a prescrever uma reforma sistêmica do setor por meio da centralização da defınição da matriz curricular, da descentralização administrativa (operacional) e, sobretudo, da adoção de instrumentos de avaliação baseados em indicadores (métricas) de aprendizagem quantificáveis e comparáveis nacional e internacionalmente. A participação do setor privado (lucrativo e sem fins lucrativos) na 
educação foi exaltada como parte da sua conversão em um setor de serviços competitivo e globalizado (MUNDY; VERGER, 2016; BONAL, 2002; VERGER; JONES, 2007; HEYNEMAN, 2007; BANCO MUNDIAL, 1996).

A visão hipermercadista da década anterior - quanto mais Estado, menos mercado - cedeu lugar à noção de complementariedade entre Estado e mercado, segundo a qual o Estado "eficaz" é aquele que atua como "parceiro" do capital, devendo criar e garantir as condições ótimas para a maximização do lucro privado (BANCO MUNDIAL, 1991, 1997). Esta formulação associou-se rapidamente ao discurso de que o sucesso da liberalização econômica depende da "boa governança" entre atores públicos e privados em torno de objetivos tangíveis, legitimando a imbricação direta do setor privado no interior da gestão pública (BANCO MUNDIAL, 1992), a fim de moldá-la por dentro à sua imagem e semelhança. A partir de então, o Banco passou a fazer uso crescente dos empréstimos de ajuste estrutural, utilizando-os como instrumentos para reformar as políticas dos países clientes. Assim, governança passou a ser o slogan geral que aglutinava as políticas, as técnicas e os saberes necessários para impulsionar e dirigir a mudança social dentro dos Estados sem o exercício de controle político direto (WILLIAMS; YOUNG, 1994; PEREIRA, 2016).

Desde o ano de 2011, o Banco Mundial enfatiza que o principal desafio educacional não consiste mais na universalização do acesso à educação básica (bastante avançada, ainda que incompleta), mas sim na universalização da aprendizagem (BANCO MUNDIAL, 2018, 2011; ROBERTSON, 2012). Curiosamente, do vasto repertório de recomendações educacionais da entidade para atingir esse fim, o que se destaca não é a pedagogia, mas sim a gestão. De fato, a abordagem do Banco busca incidir no desenho e na dinâmica da gestão escolar e do sistema educacional, concebendo a "reforma educacional" a partir de princípios administrativos, e não pedagógicos ou políticos. A ausência de qualquer consideração séria sobre o poder e a política resulta num tratamento administrativista da educação, que exclui da discussão as transformações econômicas, políticas e sociais provocadas por décadas de liberalização econômica.

Não por acaso, a chamada Nova Gestão Pública (NGP) é assumida e impulsionada pelo Banco Mundial como referência para uma reforma global do setor público. Essa vertente aplica conhecimentos e instrumentos da gestão empresarial ao setor público, com o objetivo de aumentar a eficiência, a eficácia e a prestação de contas. Ou seja, a boa gestão pública é aquela que mimetiza as práticas e visões da grande empresa privada. A NGP promove como princípios a separação radical das funções de provedor, executor e usuário, a fragmentação dos serviços públicos em unidades de gestão mais autônomas (para que concorram por recursos) e a gestão baseada em resultados aferíveis por métricas. Nessa lógica, o Estado não deve ser o único (ou mesmo o principal) fornecedor de educação, e a educação pública pode ser prestada por entidades privadas sem fins lucrativos, mediante parcerias público-privadas, ou delegada a escolas privadas financiadas com dinheiro público por meio de vouchers (VERGER; NORMAND, 2015; ROBERTSON; VERGER, 2012). Em outras palavras, tais princípios, quando aplicados, racionalizam a imbricação do setor privado diretamente no setor público e estabelecem a competitividade generalizada entre instituições públicas, por um lado, e entre os setores público e privado, por outro. As diretrizes na NGP têm pretensões de aplicação global, mas se traduzem em 
políticas distintas nos diferentes níveis de governo, assumindo significados e implicações diferenciados, segundo as circunstâncias locais e os interesses em disputa.

\section{O Banco Mundial na educação brasileira: entre o ajuste e a pandemia}

A atuação do Banco Mundial na educação brasileira envolve aconselhamento político, assistência técnica e pesquisa especializada, além de empréstimos direcionados a projetos e políticas públicas. Sem dúvida, seguir o dinheiro é mais fácil do que avaliar a magnitude as atividades "não financeiras", bem como a influência intelectual das publicações do Banco. Em todo caso, um exame da carteira de empréstimos para o país no período de janeiro de 1989 a julho de 2020 revela alguns aspectos interessantes ${ }^{3}$. Em primeiro lugar, o total da carteira é de US\$ 46,3 bilhões em 324 operações, dos quais apenas US\$2,1 bilhões $(4,5 \%)$ em 15 operações para a educação ${ }^{4}$. Percebe-se que, frente ao PIB nominal brasileiro (US\$ 1,8 trilhão) ou ao orçamento autorizado do Ministério da Educação (MEC) em 2019 (R\$ 122 bilhões, cerca de US\$ 23 bilhões) ${ }^{5}$, os montantes não são expressivos. Significa dizer que o dinheiro não é o produto principal do Banco Mundial, mas sim um veículo para difundir o que realmente importa: ideias, normas e prescrições sobre o que os governos devem ou não fazer, e de que modo, em matéria de desenvolvimento. Em segundo lugar, do total de 324 operações financeiras, 150 foram contratadas pela União (46\%), 152 por estados (47\%) e 22 por municípios (7\%). Em valores, isso totaliza U\$22,3 bilhões contratados pela União, U\$ 21,8 por estados e U\$ 2,1 bilhões por municípios ${ }^{6}$. A rigor, esta é a grande diferença do Brasil em relação aos demais países da América Latina: a importância não apenas da União, mas de estados e municípios como clientes do Banco Mundial, o que indica a complexidade e capilaridade das relações entre o poder público e segmentos da sociedade civil e do empresariado com o Banco Mundial no país ${ }^{7}$.

Em terceiro lugar, chama atenção o fato de que, de todos os governos no plano federal desde 1989, apenas os de Lula e Dilma não contrataram empréstimos para educação ${ }^{8}$, embora os governos do Partido dos Trabalhadores (em Recife) e do Partido Socialista Brasileiro (em Pernambuco), seu aliado, o tenham feito em 2012 e 2009, respectivamente ${ }^{9}$. Em matéria educacional, das quinze operações realizadas, treze foram contratadas por governantes de partidos de centro e de direita (PMDB, PSDB e PFL) ${ }^{10}$. A tabela a seguir informa a respeito dos projetos em educação financiados no período.

\footnotetext{
3 - Levantamento próprio, com base em informações disponíveis em: https://projects.worldbank.org/pt/projects-operations/projects-summary? lang=pt\&searchTerm=\&countrycode_exact=BR. Acesso em: 5 ago. 2020.

4- 0 peso de cada rubrica na carteira do Banco Mundial pode variar bastante ao longo do tempo e do país em questão. Por exemplo, durante o mesmo período, os empréstimos para educação tiveram uma importância bem maior no México (8\%) e na Colômbia (14\%) do que no Brasil.

5 - Conversão de 1 para 5,3. Em 5 ago. 2020.

6- Valores acumulados, sem correção monetária.

7- Levantamento próprio, com base em informações disponíveis em: https://projects.worldbank.org/pt/projects-operations/projects-summary?! ang=pt\&searchTerm=\&countrycode_exact=BR. Acesso em: 5 ago. 2020.

8 - 0 governo de Jair Bolsonaro não conta, pois o mandato presidencial se estende até 2022.

9- Cabe informar que, durante os governos Lula e Dilma, o Banco Mundial aprovou 183 empréstimos ao Brasil, dos quais 71 (39\%) à União.

10 - Vale acrescentar que, antes de 1989, o Banco Mundial fez apenas três empréstimos para projetos educacionais: em 1971 (P006243), no valor de US\$ 8,4 milhões; em 1974 (P006282), de US\$ 36 milhões; e em 1984 (P006338), no valor de 40 milhões, todos contratados pela União. Todavia, indiretamente, a "educação" figurou como subcomponente em inúmeros projetos setoriais diversos, principalmente os de "desenvolvimento rural".
} 
Tabela - Projetos do Banco Mundial para educação no Brasil (janeiro de 1989 a julho de 2020)

\begin{tabular}{|c|c|c|c|c|c|c|}
\hline & TÍTULO DO PROJETO & MUTUÁRIO & $\begin{array}{l}\text { ID DO } \\
\text { PROJETO }\end{array}$ & $\begin{array}{l}\text { COMPROMISSO } \\
\text { (milhões de } \\
\text { US\$) }\end{array}$ & Situação & Data da aprovação \\
\hline 1 & $\begin{array}{l}\text { Support to Upper Secondary Reform in Brazil } \\
\text { Operation }\end{array}$ & União & P163868 & 250.00 & Ativo & 14 de dezembro de 2017 \\
\hline 2 & $\begin{array}{l}\text { SWAp para o Projeto de Educação e Gestão } \\
\text { Pública de Recife }\end{array}$ & Recife & P126372 & 130.00 & Encerrado & 29 de maio de 2012 \\
\hline 3 & $\begin{array}{l}\text { PE SWAP Pernambuco Educ Results\& Account. } \\
\text { (PERA) }\end{array}$ & PE & P106208 & 154.00 & Encerrado & 14 de abril de 2009 \\
\hline 4 & $\begin{array}{l}\text { PERNAMBUCO INTEGRATED DEVELOPMENT: } \\
\text { EDUCATION QUALITY IMPROVEMENT PROJECT }\end{array}$ & PE & P069934 & 31.50 & Encerrado & 14 de outubro de 2004 \\
\hline 5 & Bahia Education Project (APL) - Second Phase & BA & P070827 & 60.00 & Encerrado & 30 de junho de 2003 \\
\hline 6 & $\begin{array}{l}\text { FUNDESCOLA IIIA (THIRD SCHOOL IMPROVEMENT } \\
\text { PROJECT) }\end{array}$ & União & P057653 & 160.00 & Encerrado & 13 de junho de 2002 \\
\hline 7 & Bahia Education Project & BA & P059565 & 69.60 & Encerrado & 20 de dezembro de 2000 \\
\hline 8 & Ceara Basic Education Quality Improvement Project & CE & P059566 & 90.00 & Encerrado & 20 de dezembro de 2000 \\
\hline 9 & Second School Improvement Project & União & P050763 & 202.00 & Encerrado & 8 de junho de 1999 \\
\hline 10 & School Improvement Project FUNDESCOLA (01) & União & P050762 & 62.50 & Encerrado & 2 de abril de 1998 \\
\hline 11 & BR-PARANA BASIC EDUCATION QUALITY & PR & P006558 & 96.00 & Encerrado & 28 de junho de 1994 \\
\hline 12 & Basic Education Quality Improvement Project & União & P006543 & 150.00 & Encerrado & 17 de maio de 1994 \\
\hline 13 & Northeast Basic Education Project (03) & União & P006452 & 206.60 & Encerrado & 23 de novembro de 1993 \\
\hline 14 & Northeast Basic Education Project (02) & União & P006427 & 212.00 & Encerrado & 13 de maio de 1993 \\
\hline 15 & Innovations in Basic Education Project & União & P006364 & 245.00 & Encerrado & 26 de junho de 1991 \\
\hline
\end{tabular}

Fonte: https://projects.worldbank.org/pt/projects-operations/projects-summary?lang=pt\&searchTerm=\&countrycode_exact=BR. Acesso em: 5 ago. 2020.

Em novembro de 2017 veio a público o relatório do Banco Mundial intitulado "Um ajuste justo: análise da eficiência e equidade do gasto público no Brasil”. Advogando a tese de que o setor público no país gasta muito e mal, o Banco apresentou um extenso rol de prescrições em favor do corte de recursos no funcionalismo público, em compras públicas, na previdência social, na assistência social e em saúde e educação, com o objetivo de manter o teto de gasto definido pela Emenda Constitucional 95/2016. 0 relatório teve ampla repercussão nos principais jornais do país, suscitando forte reação contrária (DRUCK et al., 2018, CARDOSO Jr, 2017; LOPES; ROQUE, 2017; ALMEIDA; REIS, 2017). 0 debate logo se polarizou e trouxe à cena pública a discussão sobre a consistência metodológica dos dados estatísticos que sustentavam as recomendações do Banco. 
No capítulo sobre educação, a tese central é a de que o setor público gasta muito e mal nos ensinos fundamental, médio e superior, razão pela qual o setor poderia economizar bastante se adotasse práticas do setor privado, onde, segundo o Banco, o custo por aluno é mais baixo, há mais alunos por professor, menos reprovação, menos evasão e notas relativamente mais altas em provas de larga escala. Assim, o modelo a ser mimetizado pelas escolas púbicas seria o das grandes escolas privadas situadas nas maiores cidades do país. 0 mesmo valeria para as universidades públicas federais. Ao mesmo tempo, além da gestão ineficiente, o Banco Mundial também afırma que o principal fator responsável pelo mau desempenho da educação pública é a baixa qualidade dos professores. 0 salário dos professores da educação básica foi descrito como, na média, adequado (em linha com o de países de renda per capita similar), ao passo que o salário dos professores de universidades federais foi considerado alto, acima do que é pago em países com renda per capita maior que a do Brasil (BANCO MUNDIAL, 2017a, p. 127-128).

Para o Banco Mundial, se o principal problema da educação pública não é de insuficiência de recursos, mas sim de ineficiência de gestão, seria possível melhorar o desempenho do setor gastando-se menos em todos os níveis. Nesse sentido, o relatório advoga a desvinculação dos gastos em educação de qualquer obrigação constitucional, a fim de liberar os governos de gastarem o patamar mínimo, raramente cumprido. Ademais, o Banco defende a reforma dos regimes estaduais de aposentadoria dos professores (cujos proventos seriam "relativamente generosos"), com o objetivo de reduzir o seu valor e, assim, contribuir com o ajuste fiscal (BANCO MUNDIAL, 2017a, p. 127-28).

Ao lado dessas recomendações mais gerais, o Banco Mundial também prescreveu medidas específicas para os diferentes níveis de ensino da educação pública. No caso dos ensinos fundamental e médio (onde a maioria das matrículas é ofertada pelo Estado), o Banco recomenda a não reposição de professores que se aposentarem até 2027, a fim de aumentar o número de alunos por professor (que, segundo o Banco, é muito baixo no país). Ademais, a instituição preconiza uma reforma da gestão escolar com base em três medidas: a) pagamento de bônus individual a professores e funcionários, conforme o desempenho das escolas; b) contratação de empresas privadas para fornecimento de "serviços educacionais" (escolas charter); c) implantação de parcerias público-privadas para o fornecimento de material didático, a confecção de instrumentos de avaliação, a oferta de cursos para formação de professores, entre outros. Já no caso do ensino superior (onde é o setor privado que oferta a maioria das matrículas), as recomendações do Banco Mundial são: a) reduzir o gasto público por aluno (o que obrigaria as universidades a reverem a sua estrutura de custos e buscarem recursos em outras fontes); b) cobrar mensalidades dos alunos que "podem pagar" (os 40\% mais ricos da população); c) fornecer crédito estudantil para alunos de universidades públicas; $d$ ) fornecer bolsas para os alunos mais pobres (os 40\% mais pobres da população) (2017a, p. 136-138). Note-se como o "combate à pobreza" continua sendo usado para deslegitimar o princípio da gratuidade universal da educação superior pública.

É importante observar que o relatório citado está em linha com a Estratégia 2018-23 para o Brasil, que é o documento central que orienta a relação entre a instituição e seu cliente. Datada de maio de 2017, a Estratégia 2018-23 é inteiramente ancorada na defesa, por um 
lado, de um ajuste fiscal amplo e drástico, a incidir nas políticas sociais e no funcionalismo público, e, por outro, de mudanças regulatórias que reduzam os custos do setor privado e aumentem a competitividade. No caso da educação, a grande aposta do Banco nesse documento é a reforma do ensino médio, vista como "âncora" para as demais intervenções da instituição no setor ${ }^{11}$. Além de advogar a implantação de parcerias público-privadas na gestão escolar, em nome da "autonomia" das escolas, o Banco Mundial também anuncia o fortalecimento do papel da Corporação Financeira Internacional no financiamento e na assessoria a grandes grupos empresariais de educação superior, voltados para alunos de renda média e baixa (BANCO MUNDIAL, 2017b, p. 22).

A eclosão da pandemia do Covid-19 modificou algum ponto dessa agenda? Tudo indica que não. Três razões sustentam esta hipótese.

Em primeiro lugar, o presidente do Banco Mundial afirmou que a liberação de recursos para amenizar o impacto da pandemia dependerá da adoção de políticas como a liberalização do comércio e a desregulamentação da economia (que promovam, por exemplo, mercados privados de saúde) ${ }^{12}$. Ora, políticas desse tipo têm sido prescritas ou mesmo impostas há quarenta anos pelo Banco Mundial, normalmente em parceria com o FMI, e há bastante evidência sobre os efeitos socialmente regressivos provocados ou agudizados por elas (KENTIKELENIS, 2017; LABONTÉ; STUCKER, 2016).

Em segundo lugar, o pacote de ajuda rápida anunciado pela instituição tem sido canalizado por meio da Corporação Financeira Internacional, a agência do Banco Mundial que empresta diretamente ao setor privado. A missão dessa entidade é financiar a expansão de empresas privadas, estrangeiras e nacionais, em países pobres e de renda média. No âmbito da saúde, isto implica o estímulo a parcerias público-privadas, cujo crescimento costuma ocorrer em detrimento do fortalecimento de sistemas públicos universais (RÜCKERT; LABONTÉ, 2014), o mesmo ocorrendo na educação (MUNDY; MENASHY, 2012; ROBERTSON; VERGER, 2012).

Em terceiro lugar, as prescrições do Banco Mundial para o combate à pandemia, feitas diretamente aos países clientes não questionam a agenda neoliberal, ao contrário. 0 caso do Brasil é ilustrativo, por se tratar do terceiro maior cliente histórico da instituição (atrás apenas da Índia e da China) e ser um país de renda média - que dispõe, por isso, de considerável margem de barganha com o Banco, ao contrário do que ocorre com países pobres. No extenso relatório dedicado aos impactos da Covid-19 no Brasil, o Banco Mundial (2020), a despeito da defesa de ações temporárias que resultam no aumento do gasto público, segue advogando a primazia normativa do ajuste fiscal e uma agenda ampla de reformas neoliberais. Alguns pontos dessa agenda merecem destaque: a) a desvinculação do gasto público em saúde do patamar mínimo definido constitucionalmente; b) o congelamento da folha de pagamentos do funcionalismo público, combinado com

11- Em dezembro de 2017 o Banco aprovou um empréstimo de US\$ 250 milhões para apoiar a implantação da reforma nos estados. Porém, até julho de 2020 apenas US\$ 43 milhões haviam sido desembolsados. 0 atraso se deve, ao que parece, ao fato de que a Base Nacional Curricular Comum (BNCC) tenha sido aprovada pelo Conselho Nacional de Educação - sob protestos de entidades de representação de professores e estudantes - somente em dezembro de 2018, e desde então tenha havido uma quase total paralisia do MEC. A documentação do Banco sobre 0 assunto pode ser consultada em: https://projects.worldbank.org/pt/projects-operations/document-detail/P163868. Acesso em: 6 ago. 2020.

12 - 'Remarks by World Bank Group President David Malpass on G20 Finance Ministers Conference Call on COVID-19'. March 23, 2020. https://www.worldbank.org/en/news/speech/2020/03/23/remarks-by-world-bank-group-president-david-malpass-on-g20-finance-ministersconference-call-on-covid-19. Acesso em: 28 jul.20. 
a suspensão da progressão na carreira e a interrupção (exceto em saúde e segurança) de novas contratações ${ }^{13}$; c) a finalização do ciclo de reformas previdenciárias estaduais; d) maior controle, vigilância e sanção sobre o desempenho fiscal dos entes federativos, a fim de manter o teto de gastos. 0 Banco Mundial também preconiza a retomada da agenda de reformas neoliberais - iniciada pelo governo Temer, continuada pelo governo Bolsonaro, mas paralisada pela eclosão da pandemia -, o que implica:

\begin{abstract}
A abertura continuada dos mercados para maior concorrência (além do comércio), a reforma do sistema tributário bizantino para permitir a alocação eficiente de fatores, e a reforma do ambiente de negócios de maneira mais geral. Dado o golpe significativo no espaço fiscal do país, será importante comunicar também como a agenda de consolidação fiscal será mantida, e possivelmente apertada, para atingir a meta final de recriar o espaço fiscal. No que diz respeito à política monetária, [...] será mais importante do que nunca garantir a independência de jure do Banco Central do Brasil. (BANCO MUNDIAL, 2020, p. 143).
\end{abstract}

Para tanto, o Banco Mundial anuncia que desempenhará abertamente o papel de advocacy, a fim de construir "evidências e consenso público para o desenvolvimento liderado pelo setor privado" (2017b, p. 23), o que mostra o caráter abrangente, politizado e intrusivo da sua atuação.

\title{
Conclusão
}

Este artigo discutiu a agenda educacional do Banco Mundial, argumentando que ela tem um viés economicista - centrado na formação de capital humano para o aumento da produtividade do trabalho ao menor custo possível - e se volta para a formação de economias cada vez mais competitivas e globalizadas, sob a liderança do capital privado. Segundo o Banco, a educação pública deveria ser deixada nas mãos de economistas e administradores, para que fosse conduzida mimetizando as práticas e as formas de organização de empresas privadas educacionais. Nesse sentido, para o Banco, a reforma educativa necessária à superação da atual "crise de aprendizagem" consiste na imbricação do setor privado - tanto o filantrópico como o lucrativo - no interior da educação pública, a fim de reconfigurá-la por dentro, segundo três princípios fundamentais da Nova Gestão Pública, quais sejam: a separação radical entre provedor, executor e usuário; a autonomia para as unidades que prestam serviços públicos competirem entre si e com o setor privado por recursos; e a gestão baseada em resultados aferíveis por métricas e comparáveis nacional e internacionalmente.

Tomando o caso brasileiro como referência, o artigo mostrou que a carteira de empréstimos para a educação é pouco expressiva dentro do conjunto das operações do Banco e envolve valores ínfimos, quando comparados ao orçamento anual do MEC. Significa dizer que o dinheiro funciona, basicamente, como um veículo para difundir

13 - 0 Banco Mundial (2020, p. 65) presta assessoria técnica ao governo brasileiro sobre como cortar gastos no funcionalismo público federal não realizando novas contratações. A instituição informa que faz diversas simulações sobre o assunto, ora incluindo, ora não, os profissionais da educação. 
percepções, normas, prescrições e práticas sobre o fazer em matéria de desenvolvimento, criando obrigações e prioridades para os governos federal, estaduais e municipais. É digno de nota que, dos quinze projetos para educação financiados pelo Banco desde 1989, treze tenham sido acordados por governos liderados por partidos de centro e de direita. Em catorze anos de governos do PT (Partido dos Trabalhadores), a União não contratou nenhum empréstimo para educação. Isto não exclui a priori a possível influência do Banco sobre a política educacional federal por outros meios (aconselhamento, assessoria técnica e pesquisa), mas sinaliza concretamente uma inflexão em relação aos governos anteriores.

A agenda educacional do Banco Mundial está ligada e subordinada a um programa político mais amplo, centrado na primazia normativa do ajuste fiscal e num rol de reformas econômicas de matiz neoliberal. Tal agenda está alinhada aos interesses de conglomerados empresariais brasileiros - alguns deles financiados pela Corporação Financeira Internacional - e grandes fundos globais de investimento interessados na expansão da educação como commodity. Ademais, a agenda educacional preconiza e apoia o ataque aos direitos trabalhistas dos professores da educação básica e superior, bem como a demolição do princípio da gratuidade universal do ensino superior público. Por tudo o que afirma e prescreve, tal agenda é contrária ao fortalecimento da capacidade estatal necessária para garantir, a todos os cidadãos, os direitos sociais e econômicos definidos pela Constituição de 1988.

As desigualdades educacionais existentes ao redor do mundo já eram abissais antes da pandemia, mas com ela piorarão bastante, gerando efeitos cuja duração é incerta. Essa questão estará no centro dos debates multilaterais nos próximos anos e o Banco Mundial provavelmente continuará sendo um ator político relevante no que pode advir em matéria de políticas educativas globais.

\section{Referências}

ALMEIDA, Wilson; REIS, Cristina. 0s interesses que sustentam as teses pelo fim da gratuidade no ensino superior público no Brasil. 2017. Disponível em: https://plataformapoliticasocial.com.br/ os-interesses-que-sustentam-as-teses-pelo-fim-da-gratuidade-no-ensino-superior-publico-no-brasil/. Acesso em: 05 ago. 2020.

BABB, Sarah. Behind the development banks. Chicago: The University of Chicago Press, 2009.

BONAL, Xavier. Globalización y política educativa: un análisis crítico de la agenda del Banco Mundial para América Latina. Revista Mexicana de Sociología, México, DF, v. 64, n. 3, p. 3-35, 2002.

BROAD, Robin. Research, knowledge, and the art of 'paradigm maintenance': the World Bank's Development Economics Vice-Presidency (DEC). Review of International Political Economy, London, v. 13, n. 3, p. 387-419, 2006.

CARDOSO Jr., José Celso. Nem ajuste, nem justo: réplica rápida às estórias que os economistas contam. [S. I.: s. n.], 2017. Disponível em: https://plataformapoliticasocial.com.br/nem-ajuste-nem-justo-replicarapida-as-estorias-que-os-economistas-contam/. Acesso em: 05 ago. 2020. 
DRUCK, Graça; FILGUEIRAS, Luiz; MOREIRA, Uallace. Ajuste fiscal e as universidades públicas brasileiras: a nova investida do Banco Mundial. Cadernos do CEAS, Salvador, n. 242, p. 602-634, 2017.

GWIN, Catherine. U.S. relations with the World Bank, 1945-1992. In: KAPUR, Devesh; LEWIS, John P.; WEBB, Richard C. (ed.). The World Bank: its first half century - perspectives. v. 2. Washington, DC: Brookings Institution Press, 1997. p. 195-274.

HEYNEMAN, Stephen. Historia y problemas de la creación de una política educativa en el Banco Mundial 1960-2000. In: BONAL, Xavier et al. (comp.). Globalización y educación. Buenos Aires: Miño y Dávila, 2007. p. 163-203.

JONES, Phillip W. World Bank financing of education: lending, learning and development. 2. ed. New York: Routledge, 2007.

KENTIKELENIS Alexander. Structural adjustment and health: a conceptual framework and evidence on pathways. Social Science \& Medicine, Amsterdã. v. 187, p. 296-305, 2017.

LABONTÉ, Ronald; STUCKLER, David. The rise of neoliberalism: how bad economics imperils health and what to do about it. J. Epidemiol. Community Health, London, v. 70, n. 3, p. 312-318, 2016.

LOPES, Hedibert; ROQUE, Tatiana. Usos e abusos dos números. Valor Econômico, 22 dez. 2017. Disponível em: https://valor.globo.com/opiniao/coluna/usos-e-abusos-dos-numeros.ghtml. Acesso em: 05 ago. 2020.

McNAMARA, Robert. A essência da segurança. São Paulo: Ibrasa, 1968.

MUNDY, Karen; MENASHY, Francine. The role of the International Finance Corporation in the promotion of public private partnerships for educational development. In: ROBERTSON, Susan L. et al. (ed.). Public private partnerships in education. Northampton: Edward Elgar, 2012. p. 81-103.

MUNDY, Karen; VERGER, Antoni. The World Bank and the global governance of education in a changing world order. In: MUNDY, Karen et al. (ed.). The handbook of global education policy. Chichester: Wiley Blackwell, 2016. p. 335-356.

NAíM, Moisés. Latin America: the second stage of reform. Journal of Democracy, Washington, DC., v. 5, n. 4, p 32-48, 1994.

PEREIRA, João Márcio Mendes. 0 Banco Mundial como ator político, intelectual e financeiro (19442008). Rio de Janeiro: Civilização Brasileira, 2010.

PEREIRA, João Márcio Mendes. Recycling and expansion: an analysis of the World Bank agenda (19892014). Revista Brasileira de Educação, London, v. 37, n. 5, p. 818-839, 2016.

ROBERTSON, Susan. A estranha não morte da privatização neoliberal na estratégia 2020 para a educação do Banco Mundial. Revista Brasileira de Educação, Rio de Janeiro, v. 50, n. 17, p. 283-302, 2012. 
ROBERTSON, Susan; VERGER, Antoni. A origem das parcerias público-privada na governança global da educação. Educaçao \& Sociedade, Campinas, v. 21, n. 33, p. 1133-1156, 2012.

RÜCKERT, Arne; LABONTÉ, Ronald. Public-private partnerships (PPPs) in global health: the good, the bad and the ugly. Third World Quarterly, London, v. 35, n. 9, p. 1598-1614, 2014.

STERN, Nicholas; FERREIRA, Francisco. The World Bank as 'intellectual actor'. In: KAPUR, Devesh et al. (ed) The World Bank: its first half century - perspectives. v. 2. Washington, DC: Brookings Institution Press, 1997. p. 523-610.

TOUSSAINT, Eric. Banco Mundial: el golpe de Estado permanente. Madrid: El Viejo Topo, 2006.

VAN WAEYENBERGE, Elisa; FINE, Ben. A Knowledge Bank? In: BAYLISS, Kate et al.(eds.) The political economy of development: the World Bank, neoliberalism and development research. London: Pluto Press, 2011. p. 26-48.

VERGER, Antoni; BONAL, Xavier. La estrategia educativa 2020 o las limitaciones del Banco Mundial para promover el "aprendizaje para todos. Educação \& Sociedade, Campinas, v. 32, n. 117, p. 911-932, 2011.

VERGER, Antoni; NORMAND, Romuald. Nueva gestión pública y educación: elementos teóricos y conceptuales para el estudio de un modelo de reforma educativa global. Educação \& Sociedade, Campinas, v. 36, n. 132, p. 599-622, 2015.

WILLIAMS, David; YOUNG, Tom. The World Bank and the liberal project. Political Studies, v. 42, n. 1, p. 84100, 1994. Disponível em https://onlinelibrary.wiley.com/doi/abs/10.1111/j.1467-9248.1994.tb01675.x. Acesso em: 05 ago. 2020.

Recebido em: 11.08.2020

Aprovado em: 20.10.2020

João Márcio Mendes Pereira é doutor em história pela Universidade Federal Fluminense (UFF), Professor Associado do Departamento de História e do Programa de Pós-Graduação em História da Universidade Federal Rural do Rio de Janeiro (UFRRJ). Bolsista de Produtividade do CNPq (PQ 2) e Jovem Cientista da FAPERJ. Coordenador do Núcleo de Estudos sobre Capitalismo, Poder e Lutas Sociais (NECAP). 